\title{
LA GRAMÁTICA DE LAS PASIONES EN LA ERA DE LA IGUALDAD:
}

\section{Tocqueville acerca del patbos democrático.}

\section{Juan Antonio González de Requena Farré*}

Resumen: El pathos de la democracia moderna ha sido descrito de diversos modos, aunque comúnmente en un sentido unívoco. A veces, se dice que la era de la igualdad exhibe una reflexividad y un autocontrol desapasionados; otras veces, la modernidad es retratada como un proceso de exacerbación de los deseos, o como una gran transformación de las pasiones en intereses razonables. Además, las pasiones democráticas son vistas frecuentemente como pequeños sentimientos domésticos, alienados de la esfera pública, gestionados en una intimidad clausurada, y sujetos a una administración tutelar. Tocqueville -quien fue un testigo único y privilegiado de la transición del pathos aristocrático a las pasiones democráticas- nos suministra una sutil interpretación de los variados matices y los complejos vínculos que configuran los afectos modernos. En este artículo, analizamos la prognosis de Tocqueville acerca del curso del pathos democrático, pero también prestamos atención a sus temores relativos a una gestión emocional tutelar.

Palabras clave: igualdad democrática, pasiones, intereses, gestión emocional

Abstract: The pathos of modern democracy has been described in several ways, tough commonly in a univocal sense. Sometimes, the age of equality is said to exhibit a dispassionate reflexivity and self-control; other times, modernity is depicted as a process of exacerbation of desires, or as a great transformation of passions into reasonable interests. Moreover, democratic passions are viewed frequently as petty domestic feelings, alienated from public sphere, managed into a closed intimacy, and subject to a tutelary administration. Tocqueville -who was a privileged and uncommon witness of the transition from the aristocratic pathos to democratic passions- provides us with a subtle interpretation of the various nuances

* Doctor en Filosofía por la Universidad Complutense de Madrid, Magíster en Ciencias Sociales por la Universidad ARCIS (Artes y Ciencias Sociales) de Chile y Licenciado en Filosofía y Letras por la Universidad Autónoma de Madrid. Trabaja como docente en la Universidad Austral de Chile, y ha publicado algunos artículos en revistas indexadas de filosofía y humanidades. Correo electrónico: jagref8@gmail.com 
and complex bonds which shape modern affections. In this article we analyze Tocqueville's prognosis on the course of democratic pathos, but we also pay attention to his fears concerning an emotional tutelary management.

Key words: democratic equality, passions, interests, emotional management

\section{Cartografías del patbos moderno}

El orden pasional desplegado a través de los procesos de modernización resulta bastante más complejo de lo que dan a entender algunas versiones del mito de una modernidad desencantada y desafecta, tan desapegada como íntegramente orquestada por cierta racionalidad instrumental y calculadora. Sin duda, no podemos desconocer que, a través del despliegue civilizatorio moderno, ha tenido lugar cierta racionalización de los afectos y se ha ido generalizando una forma desapasionada de autodominio. En ese sentido, Norbert Elias ha expuesto convincentemente el modo en que el progreso civilizatorio implica no sólo una interiorización de las coacciones externas, sino también la generalización y estabilización de las regulaciones de la vida afectiva, de manera que se privilegia la contención de las pasiones y emociones espontáneas ${ }^{1}$. Se trata de desarrollos asociados a procesos civilizatorios modernos como la creciente interdependencia de las interacciones sociales y la monopolización de la violencia física. Y es que -según Elias- la pacificación de algunos ámbitos de cooperación social aportaría el trasfondo para que los individuos asuman una planificación de cadenas de interrelaciones cada vez más amplias, de modo que su comportamiento se regularice bajo un aparato de autocontrol cada vez más estable.

Por lo demás, así como se transformaría el sistema emotivo de los individuos -en el sentido de una contención desapasionada al servicio de la previsión de largo plazo-, también se neutralizaría afectivamente la observación de personas y cosas: ya no se respondería al sentimiento con el sentimiento, sino que se privilegiaría el entendimiento desapasionado de la naturaleza y una consideración psicológica de las personas, liberada de las

1 Elias, Norbert, El proceso de la civilización, Buenos Aires, Fondo de Cultura Económica, 1993, pp. 449-463. 
reacciones emocionales espontáneas ${ }^{2}$. Ahora bien, -para Elias- la misma deriva civilizatoria moderna que ha impulsado la creciente racionalización, la previsión técnica y la individualización, así como el autocontrol desapasionado, también ha implicado una reorganización de los miedos sociales: las tensiones y temores interpersonales se interiorizan bajo una intensa auto-coacción personal, de manera que se profundizan las experiencias de la vergüenza, los escrúpulos y el malestar ${ }^{3}$. En suma, aunque Elias asocia el proceso civilizatorio moderno a una transformación en nuestra economía afectiva, ésta no consiste en una simple neutralización emocional al alero de la generalización de un autocontrol desapasionado, sino que pasa por un desplazamiento de los afectos en el sentido de la interiorización creciente del temor y la extensión de la vergüenza.

También Albert Hirschman suministra una matizada reconstrucción de las formas de reorganización afectiva que corresponden al ethos social del Estado moderno; nuevamente, más que de una neutralización emocional, se trata de un desplazamiento y contrabalanceo pasional. El punto de partida de la reconstrucción afectiva que Hirschman describe se encuentra en el desmoronamiento del ethos heroico y en el desgaste de los motivos asociados a la persecución del honor y la gloria, que eran característicos del ideal caballeresco medieval ${ }^{4}$. La crítica moderna del ideal heroico y de la pasión aristocrática por la gloria militar coincide con la necesidad de una nueva teoría de la naturaleza humana -realista, científica y positiva- que permitiera establecer las condiciones de posibilidad del mantenimiento del Estado político y los principios del gobierno legítimo. Una opción para sostener el orden social y político consistía en que el Estado se hiciera cargo de la coerción y represión de las pasiones incontrolables; otra opción era el aprovechamiento de las pasiones -en vez de su represión-, de manera que éstas se transformasen en un factor constructivo al servicio del bien general o de los propósitos de la historia universal ${ }^{5}$. Ninguna de estas dos vías parecen suficientemente realistas, y por eso cobró vigencia una tercera solución menos propensa a los excesos normativos o a las expectativas moralistas: la utilización de ciertas pasiones inocuas para compensar a las

\footnotetext{
2 Ibid., pp. 482-499.

3 Ibid., pp. 499-506.

${ }^{4}$ Hirschman, Albert O., Las pasiones y los intereses, Barcelona, Península 1999.

${ }^{5}$ Ibid., pp. 37-43.
} 
pasiones destructivas; esto es, el control de las pasiones mediante su división y confrontación. Por cierto, esas pasiones compensatorias que no eran ajenas a la naturaleza humana fueron concebidas como "intereses"; se trataba de aquellas aspiraciones humanas inocuas y pacíficas (no sólo la búsqueda del bienestar material), marcadas por cierto elemento de reflexión y cálculo en la persecución de su propósito.

Aunque se había originado en el léxico de la ciencia política moderna, -según Hirschman- este concepto de interés (la motivación razonada y el entendimiento disciplinado que permiten acrecentar el poder y la influencia), se extrapoló progresivamente a todas las formas de persecución ordenada y razonable de las aspiraciones humanas, e incluso llegó a designar una forma más restringida de pasión vinculada a la eficacia calculable: el afán de lucro. En ese sentido, el amor por el dinero y el ánimo de enriquecimiento se terminaron consagrando como pasiones capaces de compensar y controlar a otras pasiones más violentas, tales como la ambición de poder, el deseo de dominación o la lujuria ${ }^{6}$. De ese modo, el interés introdujo una forma híbrida de motivación entre una motivación pasional (que podía resultar destructiva) y, por otra parte, una motivación meramente racional (que podía ser ineficaz); en tanto que aspiración, el interés aunaba la dirección de la razón y la intensidad de la pasión 7 . Con el léxico de los intereses en general -y el amor al dinero, de modo paradigmático- se puso de manifiesto una motivación realista para el comportamiento humano y se estableció un trasfondo de aspiraciones compatible con el mantenimiento de un orden social viable. No en vano, los intereses $-\mathrm{y}$, particularmente, el interés económico- cuentan con la ventaja de hacer predecibles, constantes y calculables, las actividades y expectativas humanas. Según Hirschman, en suma, se terminó considerando que el afán de lucro y el interés material resultaban más inofensivos y benignos que las acciones motivadas por pasiones turbulentas; éstas no fueron eliminadas, sino tan sólo desplazadas por la tranquila aspiración a la riqueza racionalmente conducida y por el inocuo interés 8 .

\footnotetext{
6 Ibid., pp. 44-64.

7 Ibid., p. 66.

${ }^{8}$ Ibid., pp. 71-89.
} 
Existen otras descripciones de la reorganización afectiva que se asocia a los procesos de modernización. En el caso de Agnes Heller, la reconstrucción de las dinámicas afectivas modernas enfatiza el modo en que se consolida una gestión doméstica de los sentimientos en el mundo burgués. Como contexto histórico-social, la moderna sociedad burguesa se caracteriza -según Heller- por realizar una "sociedad pura” y dinámica, esto es, un tipo de vinculación social en que no existe una jerarquía de rangos fijos que determinen el destino individual; cada individuo parece ser formalmente libre de decidir sus prescripciones, adscripciones, tareas y trayectorias. De ahí que, en la sociedad moderna, se produzca cierta desestructuración de las asignaciones de roles y de los cánones afectivos compartidos que habían enmarcado el quehacer de los individuos en las comunidades orgánicas del Antiguo Régimen. Como contrapartida, en el mundo burgués se flexibilizan y diversifican las posibles relaciones entre las adscripciones, las objetivaciones y los sentimientos. Según Heller, la individualización emocional en el mundo burgués deviene reflexiva y aparece sujeta a la modelación individual de los matices sentimentales, que se exploran el refugio de una intimidad tan enquistada como alienada. En ese sentido, cabe hablar de una gestión doméstica del sentimiento, en virtud de la cual tiene lugar cierto repliegue subjetivo de las experiencias afectivas ${ }^{9}$.

En la formación social burguesa, se cultiva -según Heller- el mundo íntimo de una experiencia emocional privatizada como interioridad sentimental; de ese modo, las opciones de vivencia del sentimiento se desconectan del ámbito social del mercado, en el que se despliegan las relaciones de intercambio mercantil y la racionalidad instrumental. Desde esa perspectiva, el individuo burgués se encuentra atravesado por cierta fractura entre el cultivo de la interioridad del sentimiento y, por otra parte, las reservas ante la expresión de lo emocional que se erigen en nombre de una razón calculadora y de las condiciones objetivas de la estructura social. Se trata de una experiencia emocional enajenada del mundo social y de los trasfondos afectivos compartidos. No en vano, la nostalgia (la añoranza de algo perdido y la consciencia de una ausencia) se perfila con frecuencia como el sentimiento burgués por antonomasia ${ }^{10}$. Por lo demás, no es de extrañar que la gestión doméstica del sentimiento en el mundo burgués

${ }^{9}$ Heller, Agnes, Teoría de los sentimientos, Barcelona, Fontamara, 1982, pp. 237-243. ${ }^{10}$ Ibid., pp. 238 y 241. 
presente una tensión antinómica que entrelaza la auto-elección con la autoabsorción emocional; la flexibilidad afectiva, con la rigidez intolerante ante los otros; la interioridad sentimental, con la auto-indulgencia ensimismada y egoísta. La gestión del sentimiento en el mundo burgués aparece, así, inexorablemente escindida entre los requisitos de una racionalidad instrumental alienante y las demandas de una auto-expresión sentimental alienada. Además, al refugiarse en la interioridad del sentimiento, así como en la intimidad del autoconocimiento y del autoanálisis emocional, la experiencia sentimental burguesa corre el riesgo adicional de transformarse en una gestión netamente narcisista y doblemente alienada de los mundos social e intersubjetivo ${ }^{11}$.

En todo caso, la reorganización pasional que tiene lugar en la modernidad no sólo consiste en cierto des-apasionamiento del autocontrol afectivo, en el contrabalanceo de las pasiones violentas mediante los intereses calculables, o en el repliegue en un cultivo íntimo de la interioridad sentimental. Como Remo Bodei ha puesto de manifiesto, la cartografía pasional de la modernidad también registra una marcada exacerbación del deseo, de las pulsiones adquisitivas y, por ende, una extensión de las insatisfacciones. La circulación masiva de mercancías y el acceso extendido a bienes de consumo en la sociedad moderna se traduce en una cada vez mayor transparencia y visibilidad de los objetos de deseo; pero también introduce una acusada proliferación, ilimitación y banalización de los impulsos adquisitivos (esa pleonexia o afán insaciable de posesión, que las éticas clásicas repudiaban) ${ }^{12}$. De ese modo, los deseos multiplicados, las expectativas desmesuradas y las fantasías indeterminadas de satisfacción, ganarían terreno frente a las pasiones espontáneas y explosivas, frente a las frías pasiones de los intereses calculables, así como frente a los cálidos sentimientos cultivados en la intimidad.

$\mathrm{Y}$ es que los deseos se caracterizan -según Bodei- por una particular movilidad e inquietud; no sólo resultan imprevisibles e indeterminables debido a su ausencia de localización precisa, al no perseguir la satisfacción determinada de alguna necesidad específica, sino que además están marcados por la carencia constitutiva del objeto, por cierto vacío y por una

${ }^{11}$ Ibid., pp. 257-270.

12 Bodei, Remo, Una geometria de las pasiones, Barcelona, Muchnik, 1995, pp. 20-23. 
investidura imaginaria de sus inciertas opciones de cumplimiento. Por lo demás, cuanto mayor es la movilidad de los procesos sociales y cuanto más acelerado se torna el tiempo histórico, tanto mayor es la incertidumbre del futuro y, por ende, la exacerbación e hipertrofia de los deseos. De ese modo, con el despliegue de los procesos de modernización, no sólo vemos extralimitarse la promoción masiva de deseos, sino que, también, vemos irrumpir un tipo de individualización emocional menos contenida y autocontrolada; se perfilan individuos tan incontinentes y versátiles, como potencialmente narcisistas y lábilmente incongruentes, al no poder distinguir entre sus expectativas imaginarias o proyecciones del deseo y, por otra parte, las limitaciones reales y las vinculaciones exteriores ${ }^{13}$.

Ahora bien, la deriva social del capitalismo moderno ha sido algo más que una gigantesca empresa de mercantilización y racionalización de todas las esferas del mundo vital, en virtud de la cual nuestras pasiones se reorganizarían como intereses calculables, pulsiones adquisitivas exacerbadas o cálidos sentimientos cultivados en el repliegue de la intimidad. Como ha observado Eva Illouz, en la modernidad tardía, la conducta económica ha sido cada vez más moldeada por el ámbito de las emociones, en virtud de una auténtica "emocionalización de la conducta económica"14. En la actualidad, se perfilaría cierto "capitalismo emocional", basado en la jerarquización, gestión instrumental y capitalización de competencias emocionales como el autocontrol, la empatía, la comunicación o el trabajo en equipo. En ese sentido, las dinámicas emocionales y económicas terminan configurándose recíprocamente; las pautas de las relaciones emocionales interpersonales se entrelazan con las pautas de las relaciones económicas, y conquistan un lugar central en el modo de producción social $^{15}$.

Según Eva Illouz, no sólo se ha difundido cierto ethos terapéutico que consagra el estilo emocional de la autoexploración íntima y del auto-cuidado interior, así como de la autoexpresión emocional sin trabas, de la empatía y la comunicación relacional. Además, se han codificado, normalizado y jerarquizado ciertos estilos emocionales, mediante test psicológicos que

${ }^{13}$ Ibid., pp. 27-31.

${ }^{14}$ Illouz, Eva, La salvación del alma moderna, Buenos Aires, Katz Editores, 2010, p. 83.

${ }^{15}$ Ibid., pp. 83-84. 
cosifican la fluidez de las pasiones y omiten el involucramiento contextual de la experiencia afectiva. Por otra parte, se gestionan instrumentalmente las relaciones humanas, de manera que las relaciones sociales de producción resultan concebidas en el marco de las relaciones personales, emocionales y psicológicas (con la consiguiente invisibilización de los conflictos y relaciones de poder que atraviesan la vida laboral cotidiana). De esa manera, el capitalismo emocional contemporáneo sanciona ciertos modelos de manejo de los sentimientos; se valoran la conversación positiva, el abrigar pensamientos positivos respecto a uno mismo y los demás, el ser agradable y amigable, las estrategias para congraciarse con los otros, la interdependencia afectiva, así como el establecimiento de confianza recíproca. En fin, -para Eva Illouz- la plena alienación de la experiencia afectiva parece consumarse en nombre de una invasiva retórica de lo emocional, puesta al servicio de una mercantilización de los recursos personales que alcanza hasta la administración y comercialización de los estilos emocionales. Se consagra así una identidad personal -autocontrolada y empática- tan gerencial, como íntegramente administrada y relacionalmente dependiente ${ }^{16}$.

\section{Las metamorfosis del patbos democrático, según Tocqueville.}

Cuando se trata de comprender el complejo entramado de las transformaciones afectivas asociadas a los procesos de modernización, la obra de Tocqueville resulta sumamente instructiva. A través de sus análisis comparativos de los derroteros de la revolución democrática moderna, se accede a un vívido retrato del tránsito del espíritu aristocrático del Antiguo Régimen, al ethos social de la era de la igualdad. Tocqueville -en consonancia con la filosofía política clásica- continúa adscribiendo a los regímenes sociopolíticos de la democracia y la aristocracia ciertos tipos humanos al igual que determinados afectos primordiales y modos de conducirse. En ese sentido, el pathos fundamental del sujeto aristocrático estaría marcado por la magnanimidad y el anhelo de excelencia, en tanto que el sentimiento democrático tiene como horizonte la ampliación y simplificación de las

${ }^{16}$ Ibid., pp. 98-138. 
relaciones entre individuos semejantes ${ }^{17}$. En fin, el asunto de que se hace cargo Tocqueville es, en gran medida, cierta modificación en el pathos sociohistórico, tal y como se revela en las costumbres, las instituciones y el espíritu. Pero las transformaciones en el pathos socio-histórico no constituyen únicamente un asunto temáticamente central; además, las pasiones humanas desempeñan un importante rol en los procedimientos interpretativos de Tocqueville, pues no sólo forman parte esencial de los mecanismos explicativos que el autor introduce sino que también conforman los patrones de significado que le confieren sentido a las acciones humanas. No en vano Tocqueville pretende hacer inteligibles las actividades y obras humanas, no mediante una simple descripción fáctica de nexos causales, sino a través de la vívida comprensión de los hábitos, necesidades y sentimientos de los actores; de ahí que resulte crucial la aprehensión profunda de las pasiones ${ }^{18}$. Pero las pasiones humanas no constituyen únicamente el asunto a comprender y una vía de interpretación en las meditaciones de Tocqueville; también marcan su escritura, cuyo estilo literario combina magistralmente el cuidado de las formas con el apasionamiento, la vívida emoción y la resonancia del sentimiento intenso. No es de extrañar, pues, que los significantes de la "pasión" y el "sentimiento" atraviesen reiteradamente el texto y enmarquen su sentido.

Por lo demás, Tocqueville parece asumir una posición sumamente ambivalente ante los desplazamientos afectivos y la reorganización de las pasiones que caracterizan a la revolución democrática moderna. Su punto de vista parece oscilar entre la duda inquieta, la neutralidad distanciada y la preocupación por moderar las tensiones que acarrea la era de la igualdad. No obstante, la moderación política de Tocqueville -internamente vinculada con su propósito de moderar algunas inclinaciones indeseables del ethos social democrático- apenas puede contener su incesante inquietud, los anhelos contradictorios de su espíritu y su inmoderada pasión por la libertad. No se trata únicamente de que Tocqueville haya incorporado la ansiedad, el desasosiego y las expectativas que son propias de una época de

${ }_{17}$ Manent, Pierre, "Tocqueville filósofo político", en Nolla, Eduardo (ed.), Alexis de Tocqueville.Libertad, igualdad, despotismo, Madrid, Fundación para el Análisis y los Estudios Sociales, 2007, pp. 269-288.

18 Boesche, Roger, "Why could Tocqueville predict so well?", Political Theory, Vol. 11, $\mathrm{N}^{\circ} 1,1983$, pp. 79-103. 
transición como la que él mismo vivió. En efecto, Tocqueville compartió con algunos de sus contemporáneos la incomodidad ante ciertas formas de nivelación social y de servidumbre espiritual que amenazaban de diversos modos a la libertad; de esa manera, en el curso de la consolidación de la edad de la igualdad, mantuvo quijotescamente un anhelo inextinguible por la grandeza espiritual y las pasiones nobles. No en vano la aparente moderación de Tocqueville resulta, en el fondo, sumamente paradójica: mantiene en tensión la contención política, la neutralidad intelectual y la duda inquisitiva, así como la apasionada inquietud e insatisfacción ante el espíritu de su época. En suma, se trata de una moderación poco ortodoxa, que en ningún caso carece de coraje intelectual, de iniciativa resuelta y del anhelo de magnánimas pasiones ${ }^{19}$.

Tocqueville, que participa del pathos aristocrático en virtud de su noble alcurnia, exhibe una consciencia trágica de la irreversible erosión de aquellos rasgos notables que caracterizaban a las pasiones aristocráticas: el orgullo de sí mismo, el amor por la independencia espiritual, el amor a la gloria, el genio altivo y audaz ${ }^{20}$; pero, también, el refinamiento del gusto, la magnanimidad y generosidad ${ }^{21}$. No en vano, Tocqueville no deja de expresar cierta preocupación por el empequeñecimiento de las pasiones que parece extenderse en una era igualitaria de nivelación de los talentos y las condiciones (que es, asimismo, la época de una mediocridad generalizada). Uno de los más relevantes riesgos que se corren en la revolución democrática moderna consiste, pues, en la pérdida de las grandes pasiones, sin las cuales la democracia podría dar paso a la más penosa servidumbre. En el momento en que sólo quedan las pequeñas pasiones y los inestables deseos, la sociedad podrá lograr cierta calma, pero al precio de esa lamentable impotencia que es característica de las gastadas pasiones de la vejez ${ }^{22}$. Por eso, Tocqueville confiesa preferir la elevada ambición y la audacia apasionada por sobre los deseos mediocres y las pequeñas

${ }^{19}$ Craiutu, Aurelian, “Tocqueville's Paradoxical Moderation”, The Review of Politics, Vol. 67, n 4, 2005, pp. 599-629.

${ }^{20}$ de Tocqueville, Alexis, El Antiguo Régimen y la Revolución, Alianza Editorial, Madrid, 2004, p.152.

${ }^{21}$ de Tocqueville, Alexis, La democracia en América 1, Alianza Editorial, Madrid, 2006, p. 36.

22 Ibid., pp. 38-39. 
preocupaciones privadas; teme que en las sociedades democráticas las pasiones se empequeñezcan y el ethos compartido se torne tan tranquilo como mezquino 23 .

No obstante, Tocqueville parece matizar dicho temor en la medida en que introduce una perspectiva de conjunto compensatoria, a saber: la misma revolución democrática, que empequeñece las pasiones, difunde y generaliza los sentimientos. En fin, se gana globalmente, en virtud de la grandeza de la justicia, a pesar de que se pierde en elevación y excelencia debido a la nivelación igualitaria. Tal vez ya no haya almas enérgicas, ambiciosas, abnegadas y refinadas; sin embargo, los deseos se multiplican, los intereses se equilibran, la tranquilidad y comodidad se extienden, así como la barbarie retrocede ${ }^{24}$. Por otra parte, Tocqueville reconoce que la revolución democrática moderna no suprime la pasión, sino que simplemente reemplaza un pathos fundamental por otro: el carácter sublime de la pasión por la libertad (cuyas ventajas no se perciben inmediatamente, ni de modo continuo) da paso a una enérgica y generalizada pasión por la igualdad (que extiende los pequeños goces cotidianos y proporciona una continua tranquilidad) ${ }^{25}$.

En ocasiones, Tocqueville caracteriza la reconfiguración democrática del pathos y el empequeñecimiento igualitario de las pasiones en términos de un desplazamiento, desde la pasión intensa al sentimiento reflexivo y apacible. Semejante conversión de la pasión en sentimiento moderado tiene, a veces, saludables efectos; es lo que ocurre cuando el respeto a la autoridad no surge de una exaltada pasión irrazonable, sino de cierto "sentimiento razonado y tranquilo", que se vincula a la comprensión de que el poder democrático surge de la libre asociación y de la autolegislación de la sociedad $^{26}$. También el patriotismo de las sociedades democráticas muestra las ventajas de la transformación de la pasión en un sentimiento reflexivo. Y es que la autolegislación democrática puede despertar un amor por la patria no derivado de la pasión irreflexiva y del celo instintivo, sino surgido del

23 de Tocqueville, Alexis, La democracia en América 2, Alianza Editorial, Madrid, 2006, p. 316.

24 Ibid., pp. 421-422.

${ }^{25}$ Ibid., pp. 123-127.

${ }^{26}$ de Tocqueville, La democracia en América 1, p. 37. 
ejercicio habitual de los derechos y del cultivo del espíritu público 27 ; así, pues, este patriotismo reflexivo e ilustrado consiste en un "sentimiento reflexivo y estable"28. Por otra parte, hay manifestaciones de la conversión de la pasión en sentimiento reflexivo que entrañan indudables riesgos. Ciertamente, el egoísmo, es decir, el amor apasionado y desmedido hacia uno mismo, constituye un vicio humano (presente en toda sociedad) que se origina en la afectividad y el instinto ciego. Como contrapartida, el individualismo -esa pequeña pasión democrática que lleva al aislamiento y la reclusión en la intimidad de la familia y de las amistades- es un "sentimiento reflexivo y apacible", que se asocia al razonamiento defectuoso, y empobrece el espíritu público de la sociedad democrática ${ }^{29}$. En suma, el sentimiento reflexivo del individualismo ilustra el tipo de pequeñas pasiones que Tocqueville despreciaba en la sociedad democrática.

Además del individualismo, existe otra pequeña pasión que -según Tocqueville- amenaza al espíritu público y a la libertad política en una sociedad democrática; se trata de esa generalizada pasión por el bienestar material, que induce el afán de satisfacer todas las necesidades y al anhelo de proveer todas las comodidades. Ahora bien, esta pequeña pasión no resulta descrita como un "sentimiento reflexivo"; se asocia al "deseo", el cual, más que conformarse con la posesión apacible de un objeto, introduce un anhelo siempre insatisfecho y un incesante temor a la pérdida. El deseo de bienestar material es una pasión acuciante en una sociedad que nivela las condiciones y difunde el acceso al bienestar, de manera que no hay quien no guste de los goces materiales, ni hay quien no tema perder el bienestar cotidiano. Para Tocqueville, de hecho, el deseo de bienestar material constituye la pasión predominante que encauza todas las pasiones en el curso de la revolución democrática moderna ${ }^{30}$. No es una pasión inmoderada, ya que, al generalizarse el amor por los pequeños goces materiales, se requiere del orden y la tranquilidad para no perderlos; de ese modo, la pasión se modera, y persigue únicamente satisfacer numerosos pequeños deseos permitidos ${ }^{31}$. No obstante, Tocqueville entendió cabalmente cómo el bienestar material

27 Ibid., pp. 341-345.

28 Ibid., p. 149.

${ }^{29}$ de Tocqueville, La democracia en América 2, pp. 128-130.

${ }^{30}$ Ibid., pp. 165-167.

31 Ibid., pp. 168-169. 
puede ir acompañado de una inquietud infinita, que no es simplemente la insatisfacción constitutiva del deseo humano (por cuanto éste se traduce en un anhelo siempre insatisfecho de un objeto ausente). La inquietud del deseo de bienestar material se vincula al hecho de que, al buscar su cumplimiento mundano, siempre se ve burlado por la brevedad de nuestra vida e inestabilidad de nuestra condición; el deseo de bienestar mundano no deja de sembrar agitación, temores y añoranzas cambiantes. Además, debido a igualdad de condiciones en la sociedad democrática, el deseo de bienestar material multiplica y amplifica las expectativas; pero esa misma igualación democrática genera una competencia entre deseos cada vez más semejantes, y la inquietud e insatisfacción aumenta incesantemente. En suma, revolución democrática y la igualación de condiciones parecen ir asociadas a la exacerbación de un deseo mimético cada más insaciable ${ }^{32}$.

La relación entre pasión e interés ocupa un lugar central en la descripción del pathos democrático moderno. Tocqueville no sólo es consciente de la ambivalencia de las pasiones humanas -que, así como pueden inspirar las mạ́s nobles gestas, a menudo suscitan los extremos del desenfreno-; también tiene presente que ya no corren tiempos para el autosacrificio sublime, el glorioso olvido de sí y el desinterés moral categórico. Ha podido observar cómo en la joven democracia americana se generalizó la idea de que la persecución del interés particular puede coincidir con el interés general, de manera que la utilidad de todos estaría vinculada con el propio bienestar. En ese sentido, la revolución democrática moderna difunde una "doctrina del interés bien entendido", que legitima el egoísmo ilustrado y cultivado, así como consagra la utilidad y el interés (en lugar de lo sublime), en tanto que criterios morales. Al fin y al cabo, la idea de que al velar por el interés ajeno se sirve al propio interés, y el juicio de que nuestro propio interés consiste en ser honrados, constituyen una doctrina al alcance del entendimiento democrático: clara, simple, sencilla y eficaz (aunque no resulte perfeccionista ni elevada). La doctrina del interés bien entendido resulta particularmente acorde con la nivelación democrática de los espíritus y de las pasiones humanas; y es que, aunque no impulsa devociones sublimes ni virtudes extraordinarias, generaliza la moderación, la previsión y el autocontrol. De ese modo, el interés bien entendido se sirve de las

32 Ibid., pp. 173-177. 
pasiones reflexivas y de los intereses razonables para moderar las pasiones impetuosas y controlar el desenfreno pasional; se trata de regular el interés personal en nombre del interés propio (que coincide con el interés general y el orden social) ${ }^{33}$.

En todo caso, Tocqueville sólo da cuenta de la extensión del egoísmo ilustrado, sin consagrarlo con fervor; parece incómodo ante la perspectiva de que el mero interés personal marque la pauta de las acciones humanas, y frecuentemente expresa la convicción de que el interés y la pasión han de vincularse. No en vano, las pasiones y los intereses aparecen a menudo en conjunción en los textos de Tocqueville; como si uno de los escenarios más temibles que se pueden pronosticar en el curso de la revolución democrática moderna consistiera en la escisión definitiva de intereses y pasiones. Ciertamente, la igualdad democrática generaliza el autointerés e inflama deseos que requieren de estabilidad social y autocontrol razonable; pero Tocqueville teme que los individuos, recluidos en el ejercicio de sus pequeños intereses domésticos, dejen de experimentar el impulso de las grandes pasiones públicas que animan y renuevan el ethos social ${ }^{34}$. También es de temer que las pasiones se desvinculen del interés, tornándose extremas y desenfrenadas, como ocurre en el caso de la irreligiosidad furibunda, que tal vez sirve a algunas pasiones impetuosas, pero no a los intereses razonables de los seres humanos ${ }^{35}$.

Sin duda, Tocqueville cree que la revolución democrática moderna no naufragará en su propio curso, siempre y cuando consiga atraer, aunar y moderar, tanto las pasiones públicas como los intereses particulares. Por eso, Tocqueville le confiere un rol tan relevante al entusiasmo religioso; y es que la religión aporta una respuesta a las más profundas y enaltecedoras pasiones humanas, como la insatisfacción existencial y el deseo de vivir, que engendran la esperanza y el anhelo de trascendencia, así como el sentimiento de consuelo ${ }^{36}$. Además, la fe religiosa puede incitar el más apasionado amor por la independencia espiritual y por la libertad política, así como consagra

\footnotetext{
33 Ibid., pp. 157-161.

${ }^{34}$ Ibid., p. 335.

35 de Tocqueville, La democracia en América 1, p. 423.

${ }^{36}$ Ibid., pp. 426-427.
} 
el espíritu público ${ }^{37}$. Por otra parte, el entusiasmo religioso es capaz de aliarse con el interés bien entendido, para difundir un razonable autocontrol honesto y conducir a los individuos de manera que no sucumban a las pasiones extremas. Así, pues, -según Tocqueville- el interés bien entendido converge con el entusiasmo religioso y conduce a la religión, del mismo modo que la religión se sirve del interés para guiar a los individuos, favoreciendo la libertad y el orden públicos ${ }^{38}$.

Del mismo modo que las pasiones y los intereses, o los deseos y los sentimientos, también el afecto interpersonal está sujeto a profundas transformaciones en el curso de la revolución democrática moderna. No en vano, la democracia parece forjar una sociedad pura, sustentada en los afectos interpersonales naturales; al fin y al cabo la sociedad democrática parece expresar la naturaleza humana en su máxima simplicidad y en forma pura $^{39}$. La igualdad democrática erosiona todas las convenciones sociales y jerarquías artificiales del Antiguo Régimen, de manera que los sentimientos de dependencia personal asociados al ethos aristocrático sucumben. De ese modo, el pathos democrático relaja las dependencias e intereses sociales, así como estrecha los afectos naturales, tanto en el seno de la familia, como en las relaciones de pareja. En la sociedad democrática, las relaciones familiares ya no se asocian al sentimiento de dependencia patriarcal o al interés patrimonial, sino que se hacen más íntimas y dulces, dando paso al amor benigno y a la ternura fraternal ${ }^{40}$. También las relaciones de pareja en la sociedad democrática se sustentan en el afecto apacible, en la simpatía mutua y en la fidelidad, más que en los arreglos artificiales o en las condiciones sociales ${ }^{41}$. En suma, la misma revolución democrática moderna, que borra las diferencias de intereses y las obligaciones jerárquicas, permite que se expresen los lazos humanos naturales; posibilita que los individuos cada vez más igualados en su condición- tomen conciencia de su semejanza mutua, extendiendo los sentimientos de simpatía mutua, la compasión

${ }^{37}$ Ibid., pp. 419-422.

38 de Tocqueville, La democracia en América 2, pp. 162-164.

${ }^{39}$ Mélonio, Françoise, "Tocqueville and the French", en Welch, Cheryl B. (comp.), The Cambridge Companion to Tocqueville, New York, Cambridge University Press, 2006, p. 349.

40 de Tocqueville, La democracia en América 2, pp. 245-252.

${ }^{41}$ Ibid., pp. 262-267. 
humanitaria y la camaradería humana ${ }^{42}$. En todo caso, aunque los afectos interpersonales democráticos parezcan fundarse únicamente en la simpatía natural, el estado social democrático no conforma una masa indiferente de individuos iguales. Y es que la misma revolución democrática, que consolida una esfera pública inclusiva, restringe los círculos sociales y las relaciones privadas, introduciendo todo tipo de pequeños reagrupamientos y camarillas sociales; las solidaridades sociales se multiplican fluidamente sin más base que ciertas semejanzas en el gusto o ciertas simpatías comunes ${ }^{43}$.

En el curso de la revolución democrática moderna, la naturalización del sentimiento resulta solidaria de una estetización de las pasiones naturales de la humanidad. Según Tocqueville, en este sentido, la poesía democrática no se refiere a gestas heroicas, individuos sublimes o asuntos sobrenaturales y sobrehumanos (como ocurría en la sociedad jerárquica del Antiguo Régimen, cuyo imaginario estaba poblado por un nutrido repertorio de entidades intermedias y agentes secundarios idealizados); simplemente retrata la conmovedora naturaleza humana y las insondables pasiones de la humanidad, con todos sus contrastes, grandezas y miserias ${ }^{44}$. Por otra parte, a diferencia del elevado deleite que en el Antiguo Régimen se experimentaba a través el cultivo de la forma y el refinamiento del estilo, el gusto artístico en una sociedad democrática busca la excitación de las pasiones, la intensa emoción sentimental y la simpatía inmediata con los personajes ${ }^{45}$. En suma, parece que el imaginario democrático estetiza el pathos natural, así como naturaliza y simplifica el sentimiento del gusto.

Tal vez, la más inspirada prognosis que Tocqueville formuló acerca del curso del pathos democrático concierne al modo en que el disfrute de las pequeñas pasiones e intereses cotidianos -así como la exacerbación del deseo de bienestar material y el repliegue intimista del sentimiento- podrían resultar funcionales a nuevas formas de servidumbre y de alienación política, caracterizadas precisamente por basarse en el paternalismo benigno y la

42 Zetterbaum, Marvin, “Alexis de Tocqueville”, en Strauss, Leo, y Cropsey, Joseph (comp.), Historia de la filosofía política, Fondo de Cultura Económica, México D. F., 1993, pp.721-722.

43 Ibíd., pp. 275-277.

44 Ibid., pp. 92-99.

${ }^{45}$ Ibid., pp. 78-79 y 106. 
tutela emocional. Ciertamente, el escenario que más temía Tocqueville era la consolidación de un despotismo democrático tutelar y benevolente; se trataría de una administración omnipresente y centralizada, preocupada de regular todos los detalles de la felicidad de los individuos (tan aislados en el seno de una masa indiferente, como recluidos en una intimidad enquistada). El despotismo democrático velaría pastoralmente por las necesidades, intereses y bienestar de todos; pero, sobre todo, procuraría que los individuos gocen y únicamente piensen en gozar, volcados en sus pequeños placeres domésticos ${ }^{46}$. Semejante tutela emocional coincide, pues, con la administración social de las pasiones moderadas, con la domesticación y privatización de los sentimientos, así como con la exacerbación y canalización de los deseos. Dotado de una singular capacidad para realizar prognosis y apuntar tendencias históricas, Tocqueville tenía razones suficientes para temer una gestión emocional de lo social y una administración benevolente de las pasiones naturales de un hombre reducido a su nuda naturaleza. Nosotros, asediados por el despotismo blando de una administración emocional consumada, tenemos sobradas razones para reivindicar los temores de Tocqueville.

Recibido: 09/2011 Aceptado:03/2012

${ }^{46}$ Ibid., pp. 403-407. 